https://doi.org/10.34179/revisem.v6i1.14519

\title{
ENSINO DE PROBABILIDADE COMO OBJETO DE PESQUISA: O QUE VEM SENDO INVESTIGADO?
}

\section{PROBABILITY TEACHING AS A RESEARCH OBJECT: WHAT HAS BEEN INVESTIGATED?}

\author{
Reinaldo Feio Lima \\ Universidade Federal do Sul e Sudeste do Pará \\ reinaldo.lima@unifesspa.edu.br
}

\begin{abstract}
Resumo
Este artigo apresenta um estudo bibliográfico a respeito de Ensino de Probabilidade na Educação Estatística, tendo como objetivo identificar, caracterizar e compreender o que vem sendo investigado nas produções científicas brasileiras que abordam o Ensino de Probabilidade nas edições especiais de Educação Estatística. Os procedimentos metodológicos seguiram os pressupostos de uma Revisão Bibliográfica, por meio de dois momentos: inicialmente, foram selecionados periódicos brasileiros com publicações em Educação Estatística, e, em um período de nove anos, selecionadas as produções referentes ao Ensino de Probabilidade na Educação Estatística; posteriormente, realizou-se uma síntese a fim de evidenciar os principais focos teóricos e metodológicos. Foram analisados 29 trabalhos de 159 artigos investigados e destes emergiram duas categorias de pesquisa: em relação à fundamentação teórica e em relação às abordagens metodológicas assumidas pelos autores nos trabalhos. Para tanto, os dados foram analisados qualitativamente, utilizando um procedimento de estudo bibliográfico, com objetivo descritivo e natureza exploratória. A compreensão dessas categorias e de suas inter-relações podem tornar esse campo de estudo mais concreto para sua efetiva aplicação nas aulas de Ensino de Probabilidade.

Palavras-chave: Ensino de Probabilidade. Educação Estatística. Revisão Bibliográfica.
\end{abstract}

\begin{abstract}
This paper presents a bibliographic study about Teaching Probability in Statistical Education, aiming to identify, characterize and understand what has been investigated in Brazilian scientific productions that address Probability Teaching in special editions of Statistical Education. The methodological procedures followed the assumptions of a Bibliographic Review, through two moments: initially, Brazilian journals with publications in Statistical Education were selected, and in a period of nine years, the productions related to the Teaching of Probability in Statistical Education were selected; later, a synthesis was carried out in order to highlight the main theoretical and methodological focuses. 29 papers from 159 investigated articles were analyzed and from these two research categories emerged: in relation to theoretical foundation and in relation to methodological approaches taken by the authors in the works. For that, the data were analyzed qualitatively, using a bibliographic study procedure, with a descriptive objective and exploratory nature. Understanding these categories and their interrelationships can make this field of study more concrete for its effective application in Probability Teaching classes.
\end{abstract}

Keywords: Teaching Probability. Statistical Education. Literature Review. 


\section{INTRODUÇÃO}

No presente artigo, objetivamos sistematizar aspectos de um conjunto de pesquisas desenvolvidas no contexto brasileiro a respeito do Ensino de Probabilidade no contexto da Educação Estatística. Elegemos os últimos oito anos (2011-2019) como período de análise, tendo em vista que as pesquisas referentes a esta temática começaram a ser editadas e publicadas por sete revistas brasileiras, a saber: Boletim de Educação Matemática (BELAM); Revista de Educação Matemática e Tecnológica Ibero-americana (EM TEIA); Revista Educação Matemática Pesquisa (EMP); Revista Eletrônica Vidya (VIDYA); Revista de Ensino de Ciências e Matemática (REnCiMa); Revista Brasileira de Educação em Ciências e Educação Matemática (ReBECEM) e Revista Eletrônica de Educação Matemática (REVEMAT). Nessa direção, este artigo tem por questão problematizadora: o que vem sendo investigado sobre Ensino de Probabilidade nas edições especiais de Educação Estatística?

Para responder a essa pergunta, empregamos como delineamento metodológico uma pesquisa de cunho bibliográfico, na perspectiva de Fiorentini e Lorenzato (2006), Tozoni-Reis (2009) e Gil (2008), já que utilizamos materiais elaborados por diferentes autores sobre o tema.

Diante da relevância dessa temática e do interesse em desvelar as características e contribuições das pesquisas já desenvolvidas sobre Ensino de Probabilidade no contexto da Educação Estatística, apresentamos, neste artigo, uma revisão bibliográfica. Portanto, tivemos como objetivo central identificar, caracterizar e compreender o que vem sendo investigado nas produções científicas brasileiras que abordam Ensino de Probabilidade nas edições especiais de Educação Estatística.

Nesse contexto, o artigo está delineado de modo a apresentar: uma introdução para contextualizar a pesquisa desenvolvida, o delineamento metodológico que guiou a pesquisa, a análise dos dados, os resultados e as considerações finais.

\section{ENCAMINHAMENTO METODOLÓGICO}

$\mathrm{Na}$ busca pela compreensão sobre o objeto investigado - identificar a presença do Ensino de Probabilidade nas edições especiais da Educação Estatística no período de 2011 a 2019 -, pautamos nos pressupostos da abordagem qualitativa de caráter exploratório, a 
qual, segundo Prodanov e Freitas (2013, p.51), “tem como finalidade proporcionar mais informações sobre o assunto que vamos investigar".

Os aspectos qualitativos deste estudo têm afinidade com o que Creswell (2007, p. 186) refere: “a pesquisa qualitativa é fundamentalmente interpretativa, na qual o pesquisador faz uma interpretação dos dados”. Sendo assim, este artigo consistiu em uma abordagem qualitativa, visto que, segundo Rosa (2013, p. 41):

[...] a Pesquisa Qualitativa é uma pesquisa que não tem por objetivo imediato a generalização dos resultados obtidos. Nesse tipo de pesquisa, estamos interessados em levantar quais são as possíveis causas do evento observado pelo pesquisador, quais são as relações que determinam o comportamento de um determinado grupo ou sujeito. Ela tem um caráter exploratório, no sentido de que fazemos um mapeamento do terreno estudado, visando a sua descrição detalhada.

Do ponto de vista dos procedimentos técnicos, trata-se de uma pesquisa documental, na perspectiva de Fiorentini e Lorenzato (2006), pois utilizamos como fonte de dados as sete revistas selecionadas que editaram e publicaram edições temáticas "Educação Estatística", no período de 2011 a 2019. A esse respeito, Appolinário (2009, p. 85) afirma que "sempre que uma pesquisa se utiliza apenas de fontes documentais (livros, revistas, documentos legais, arquivos em mídia eletrônica), diz-se que a pesquisa possui estratégia documental". Ou seja, uma pesquisa que "[...] tem como principal característica o fato de que a fonte dos dados, o campo onde se procederá a coleta dos dados, é um documento (histórico, institucional, associativo, oficial, etc.)” (TOZONI-REIS, 2009, p. 30).

Para extração dos dados, critérios de inclusão foram considerados nas sete revistas selecionadas que publicaram edições temáticas "Educação Estatística", no período compreendido entre os anos de 2011 a 2019: os periódicos qualificados deveriam ser nacionais; o título, resumo ou palavras-chave do artigo investigado deveria conter ao menos um dos termos "Probabilidade" e "Ensino de Probabilidade". Da extração e monitoramento dos dados, 29 artigos foram selecionados para a constituição do corpus do artigo.

Para cada trabalho encontrado foi atribuída uma identificação alfanumérica. Após cada código, foi atribuído um número sequencial, aleatoriamente e sucessivamente (Quadro 1). 
Quadro 1 - Revista, título, autores e identificação dos dados

\begin{tabular}{|c|c|c|c|}
\hline Revista & Título & Autores & Identificação \\
\hline \multirow{6}{*}{ BOLEMA } & $\begin{array}{l}\text { Análise praxeológica dos passeios aleatórios da } \\
\text { Mônica. }\end{array}$ & $\begin{array}{l}\text { Camila Macedo Lima } \\
\text { Nagamine; } \\
\text { Afonso Henriques; } \\
\text { Miriam Cardoso Utsumi; } \\
\text { Irene Mauricio Cazorla } \\
\end{array}$ & T01 \\
\hline & $\begin{array}{l}\text { Validação de uma sequência didática de } \\
\text { probabilidade a partir da análise da prática de } \\
\text { professores, sob a ótica do enfoque } \\
\text { ontossemiótico. }\end{array}$ & $\begin{array}{l}\text { Irene Mauricio Cazorla; } \\
\text { Tânia Cristina Gusmão; } \\
\text { Verônica Yumi Kataoka }\end{array}$ & T02 \\
\hline & $\begin{array}{l}\text { O movimento das ideias probabilísticas no } \\
\text { ensino fundamental: análise de um caso. }\end{array}$ & $\begin{array}{l}\text { Jaqueline Aparecida Foratto } \\
\text { Lixandrão Santos; } \\
\text { Regina Célia Grando }\end{array}$ & T03 \\
\hline & $\begin{array}{l}\text { Uma proposta didático-pedagógica para } \mathrm{o} \\
\text { estudo da concepção clássica de probabilidade }\end{array}$ & José Marcos Lopes & T04 \\
\hline & $\begin{array}{l}\text { A presença da estatística e da probabilidade no } \\
\text { currículo prescrito de cursos de licenciatura em } \\
\text { matemática: uma análise do possível } \\
\text { descompasso entre as orientações curriculares } \\
\text { para a educação básica e a formação inicial do } \\
\text { professor de matemática. }\end{array}$ & Marcio Antonio da Silva & T05 \\
\hline & $\begin{array}{l}\text { A pesquisa sobre o ensino de probabilidade e } \\
\text { estatística no Brasil: um exercício de } \\
\text { metacompreensão. }\end{array}$ & $\begin{array}{l}\text { Renata C. Geromel } \\
\text { Meneghetti; } \\
\text { Rosemeire de Fátima } \\
\text { Batistela; } \\
\text { Maria Aparecida Viggiani } \\
\text { Bicudo } \\
\end{array}$ & T06 \\
\hline \multirow{7}{*}{ EM TEIA } & $\begin{array}{l}\text { Lançando dados e moedas: relação de } \\
\text { (in)dependência sob a ótica de crianças dos anos } \\
\text { iniciais. }\end{array}$ & $\begin{array}{l}\text { Rita Batista; } \\
\text { Rute Borba }\end{array}$ & T07 \\
\hline & $\begin{array}{l}\text { Probabilidade nos anos iniciais da educação } \\
\text { básica: contribuições de um programa de ensino. }\end{array}$ & $\begin{array}{l}\text { Tânia M. M. Campos; } \\
\text { José Ivanildo Felisberto de } \\
\text { Carvalho }\end{array}$ & T08 \\
\hline & $\begin{array}{l}\text { Um jogo e a linguagem: possibilidades para a } \\
\text { produção de conceitos sobre combinatória, } \\
\text { estatística e probabilidade com alunos do } 4^{\circ} \text { ano } \\
\text { do ensino fundamental. }\end{array}$ & $\begin{array}{l}\text { Jaqueline Lixandrão Santos; } \\
\text { Emily de Vasconcelos } \\
\text { Santos }\end{array}$ & T09 \\
\hline & $\begin{array}{l}\text { Sobre a necessidade de se iniciar } \\
\text { ensino/aprendizagem da estatística e da } \\
\text { probabilidade na infância. }\end{array}$ & $\begin{array}{l}\text { Lori Viali; } \\
\text { Mercedes Matte da Silva }\end{array}$ & $\mathrm{T} 10$ \\
\hline & $\begin{array}{l}\text { A noção de possível na probabilidade e na } \\
\text { combinatória em estudantes do ensino } \\
\text { fundamental. }\end{array}$ & $\begin{array}{l}\text { Giselda Magalhães Moreno } \\
\text { Nóbrega; } \\
\text { Alina Galvão Spinillo }\end{array}$ & T11 \\
\hline & $\begin{array}{l}\text { O ensino de probabilidade nos anos iniciais: um } \\
\text { olhar sobre a abordagem nos livros didáticos. }\end{array}$ & $\begin{array}{l}\text { Michaelle Renata Moraes } \\
\text { de Santana; } \\
\text { Rute Elizabete Souza de } \\
\text { Rosa Borba } \\
\end{array}$ & $\mathrm{T} 12$ \\
\hline & $\begin{array}{l}\text { Possibilidades de recursos para o ensino de } \\
\text { probabilidade nos anos iniciais. }\end{array}$ & $\begin{array}{l}\text { Carlos Eduardo Ferreira } \\
\text { Monteiro; } \\
\text { Maria Niedja Pereira } \\
\text { Martins } \\
\end{array}$ & $\mathrm{T} 13$ \\
\hline EMP & $\begin{array}{l}\text { Educação estatística num contexto colaborativo: } \\
\text { ensinar e aprender probabilidade. }\end{array}$ & Keli Cristina Conti & T14 \\
\hline
\end{tabular}




\begin{tabular}{|c|c|c|c|}
\hline & $\begin{array}{l}\text { Julgando sob incerteza: heurísticas e vieses e o } \\
\text { ensino de probabilidade e estatística. }\end{array}$ & $\begin{array}{l}\text { Claudio R. Oliveira; } \\
\text { Lisbeth Kaiserlian Cordani }\end{array}$ & $\mathrm{T} 15$ \\
\hline & $\begin{array}{l}\text { Aspectos filosóficos, psicológicos e políticos no } \\
\text { estudo da probabilidade e da estatística na } \\
\text { educação básica. }\end{array}$ & $\begin{array}{l}\text { Celi Espasandin Lopes; } \\
\text { Leandro De Oliveira Souza }\end{array}$ & $\mathrm{T} 16$ \\
\hline \multirow{7}{*}{ VIDYA } & $\begin{array}{l}\text { No jogo é a moeda que diz, não é a gente que } \\
\text { quer não: o que dizem crianças sobre a } \\
\text { probabilidade. }\end{array}$ & $\begin{array}{l}\text { Rita Batista; } \\
\text { Rute Elizabete De Souza } \\
\text { Rosa Borba } \\
\end{array}$ & $\mathrm{T} 17$ \\
\hline & $\begin{array}{l}\text { Prospectivas para o estudo da probabilidade } \\
\text { e da estatística no ensino fundamental. }\end{array}$ & $\begin{array}{l}\text { Celi Espasandin Lopes; } \\
\text { Luzinete De Oliveira } \\
\text { Mendonça }\end{array}$ & $\mathrm{T} 18$ \\
\hline & $\begin{array}{l}\text { Formação de professores para o ensino de } \\
\text { probabilidade: simulação conectando ideias } \\
\text { estatísticas. }\end{array}$ & Leandro De Oliveira Souza & $\mathrm{T} 19$ \\
\hline & $\begin{array}{l}\text { O uso do software gratuito Geogebra no ensino } \\
\text { e na aprendizagem de estatística e probabilidade. }\end{array}$ & Humberto José Bortolossi & $\mathrm{T} 20$ \\
\hline & $\begin{array}{l}\text { O conceito de probabilidade na formação } \\
\text { docente: uma reflexão apoiada pela análise } \\
\text { estatística implicativa. }\end{array}$ & $\begin{array}{l}\text { José Luiz Cavalcante; } \\
\text { Vladimir Lira Veras Xavier } \\
\text { De Andrade; } \\
\text { Jean-Claude Régnier } \\
\end{array}$ & $\mathrm{T} 21$ \\
\hline & $\begin{array}{l}\text { Ilusão da equiprobabilidade, aleatoriedade e } \\
\text { convergência nos processos cognitivos } \\
\text { envolvidos no raciocínio probabilístico. }\end{array}$ & $\begin{array}{l}\text { Gabriela Machado Moura; } \\
\text { Suzi Samá }\end{array}$ & $\mathrm{T} 22$ \\
\hline & $\begin{array}{l}\text { Uma revisão de literatura sobre estudos relativos } \\
\text { à probabilidade geométrica. }\end{array}$ & $\begin{array}{l}\text { Denise Ritter; } \\
\text { Ana Marli Bulegon }\end{array}$ & $\mathrm{T} 23$ \\
\hline \multirow[b]{2}{*}{ RENCIMA } & $\begin{array}{l}\text { Discussão sobre o processo de elaboração de um } \\
\text { livro paradidático para o ensino de probabilidade } \\
\text { à luz da teoria antropológica do didático. }\end{array}$ & $\begin{array}{l}\text { Ailton Paulo de Oliveira } \\
\text { Júnior; } \\
\text { Valéria Ciabotti }\end{array}$ & $\mathrm{T} 24$ \\
\hline & $\begin{array}{l}\text { Mapas conceituais na compreensão da } \\
\text { aprendizagem significativa do conteúdo de } \\
\text { probabilidade. }\end{array}$ & $\begin{array}{l}\text { Naiara Aparecida Ribeiro; } \\
\text { Hevyllyn de Assis Morais; } \\
\text { Willian Damin; Simone } \\
\text { Luccas }\end{array}$ & $\mathrm{T} 25$ \\
\hline \multirow{3}{*}{ REBECEM } & $\begin{array}{l}\text { Observações acerca de uma engenharia didática } \\
\text { de formação para o ensino de probabilidade. }\end{array}$ & $\begin{array}{l}\text { Cecilia Manoella Carvalho } \\
\text { Almeida; } \\
\text { Luiz Marcio Santos Farias }\end{array}$ & $\mathrm{T} 26$ \\
\hline & $\begin{array}{ll}\text { A inter-relação entre a estatística e } & \text { a } \\
\text { probabilidade: um estudo sobre os os } \\
\text { conhecimentos de professores de matemática do } \\
\text { ensino médio sobre a curva normal. } \\
\end{array}$ & $\begin{array}{l}\text { André Fellipe Queiroz } \\
\text { Araújo; } \\
\text { José Ivanildo Felisberto de } \\
\text { Carvalho } \\
\end{array}$ & $\mathrm{T} 27$ \\
\hline & $\begin{array}{l}\text { Acaso e probabilidades nos anos iniciais: } \\
\text { potencial dos jogos como mediadores na } \\
\text { construção do conhecimento. }\end{array}$ & $\begin{array}{l}\text { Keli Cristina Conti; } \\
\text { Sandra Gonçalves Vilas } \\
\text { Bôas }\end{array}$ & $\mathrm{T} 28$ \\
\hline REVEMAT & $\begin{array}{l}\text { Arranjos com repetição e e simulações } \\
\text { probabilísticas: obstáculos de aprendizagem. }\end{array}$ & $\begin{array}{l}\text { Giselle Corrêa de Souza; } \\
\text { Leandro de Oliveira Souza }\end{array}$ & $\mathrm{T} 29$ \\
\hline
\end{tabular}

Fonte: o autor (2020).

Para a análise dos dados selecionados para o corpus, utilizamos a análise documental, que, segundo Bardin (2009, p. 44), consiste em um:

[...] conjunto de técnicas de análise de comunicações visando obter por procedimentos sistemáticos e objetivos (sic.) de descrição do conteúdo das mensagens, indicadores (quantitativos ou não) que permitam a inferência de conhecimentos relativos às condições de produção/recepção (variáveis inferidas) destas mensagens. 
Portanto, diante deste conjunto de técnicas de análise, optamos por fazer um recorte da mesma, isto é, adotamos a Análise Categorial que, de acordo com a referida literatura, consiste na análise por categorias, que "[...] funciona por operações de desmembramento do texto em unidades, em categorias, segundo reagrupamentos analógicos" (BARDIN, 2009, p. 199). Logo, as categorias deste artigo não foram definidas a priori, mas surgiram após a análise dos dados (PUGLISI; FRANCO, 2005).

\section{RESULTADOS E DISCUSSÕES}

Por meio da leitura minuciosa dos 29 trabalhos, foi possível definir duas categorias de análise, em relação à fundamentação teórica e aos procedimentos metodológicos.

\section{Em relação à fundamentação teórica assumida pelos autores nos trabalhos}

Nesta categoria, investigamos quais foram os fundamentos teóricos representados nos trabalhos a partir do escopo analisado nesta pesquisa. Assim, em relação aos referenciais teóricos que apareceram com mais frequência nos trabalhos analisados e/ou assumidos pelos autores nos textos são: três pesquisas utilizaram a Teoria Antropológico do Didático (T01, T24 e T26), duas o Enfoque Ontossemiótico (T02 e T27), duas o Método Clínico Piagetiano (T07 e T17), uma a Fenomenologia (T06), uma o Histórico-Cultural de Vygotsky (T09), uma a Análise Estatística Implicativa (T21) e uma utilizou a Teoria da Aprendizagem Significativa (T25).

Adotaram como quadro teórico a Teoria Antropológico do Didático - TAD, de Chavallard (1996; 1999) e Chavallard, Bosch e Gáscon (2001), na organização praxeológica didática e matemática, que foi citado em três trabalhos. No T01 apresentaram uma sequência didática para trabalhar noções elementares da teoria de probabilidades para a Educação Básica. No T24 desenvolveram o processo de elaboração de tarefas para o livro paradidático "Jogando na Olimpíada Nacional de Probabilidade", para os anos finais do Ensino Fundamental. No T26 o objetivo foi construir um modelo didático de referência construído com professores sobre o ensino do conceito de Probabilidade. Os três trabalhos divergiram quanto ao objeto de estudo e seus respectivos contextos das atividades, mas convergiram quanto à análise dos dados, ou seja, ambos analisaram seus dados à luz da Teoria Antropológico do Didático - TAD, a qual situa a atividade matemática, e, 
consequentemente, a atividade do estudo em matemática, no conjunto de atividades humanas e instituições sociais (CHEVALLARD, 1999). Assim sendo, se "admite que toda atividade humana realizada regularmente pode ser descrita como um modelo único, que é resumido aqui como praxeologia" (CHEVALLARD, 1999, p. 222).

Segundo Almouloud (2010), as praxeologias são de duas espécies: matemáticas e didáticas. Na primeira, dizem respeito à realidade matemática elaborada em uma sala de aula, e na segunda referem-se ao modo de construí-la.

Em relação à Teoria do Enfoque Ontossemiótico da Cognição e Instrução Matemática (EOS) vem sendo desenvolvida há mais de uma década por Godino (2002) e colaboradores (GUSMÃO; FONT; CAJARAVILLE, 2009; GUSMÃO, 2006).

Segundo Cazorla, Gusmão e Kataoka (2011, p. 540), essa teoria "tem como propósito estudar os fenômenos derivados da transposição didática escolar, tratando de integrar aproximações teóricas a partir de pressupostos pragmáticos, antropológicos e semióticos, possibilitando uma melhor compreensão do processo de ensino-aprendizagem da Matemática"; mas, principalmente, Godino, Batanero e Font (2008), que foram citados nos dois trabalhos (T02 e T27), pois desenvolveram a teoria EOS, sobre a qual afirmam que "o ponto de partida do EOS é a formulação de uma ontologia de objetos matemáticos que contemple o triplo aspecto da matemática como atividade socialmente compartilhada de resolução de problemas, como linguagem simbólica e sistema conceitual logicamente organizado" (GODINO; BATANERO; FONT, 2008, p. 11).

Esses são traços comuns encontrados nos trabalhos selecionados. Por exemplo, o T02 analisou a validação de uma sequência didática "Os passeios aleatórios da Mônica", para ensinar conceitos de Probabilidade, na Educação Básica, a partir da prática de professores, avaliando sua pertinência quando implementada em sala de aula, sob a ótica do Enfoque Ontossemiótico. No T27 discutiram os resultados parciais de um estudo que propõe uma investigação sobre os conhecimentos didático-matemáticos de professores de Matemática do Ensino Médio, relativos à relação mútua entre a Estatística e a Probabilidade por meio da Curva Normal, desenvolvido no âmbito da teoria do Enfoque Ontossemiótico.

Os resultados destas duas investigações indicaram que a técnica de análise semiótica vislumbra resultados consideráveis para a proposta, uma vez que permite um 
olhar mais atento e detalhado sobre os objetos implicados na atividade matemática, dando lugar a uma avaliação da sequência com vistas a um melhor planejamento, delineamento e eficácia no seu uso; apontaram, também, que os professores apresentam lacunas em conhecimentos matemáticos e didáticos para o trabalho com a Curva Normal nesta etapa de escolaridade, na perspectiva de uma mobilização articulada entre os conceitos estatísticos e probabilísticos abarcados por esse modelo matemático (ARAÚJO; CARVALHO, 2019; CAZORLA; GUSMÃO; KATAOKA, 2011).

Duas investigações foram baseadas no Método Clínico Piagetiano (CARRAHER, 1988). Na primeira, os autores investigaram noções probabilísticas de crianças do $1^{\circ}, 3^{\circ} \mathrm{e}$ $5^{\mathrm{o}}$ anos, cujos dados foram obtidos a partir de entrevistas clínicas que envolviam dois jogos. $\mathrm{Na}$ segunda pesquisa, os mesmos autores tiveram como objetivo analisar compreensões de crianças do $1^{\circ}, 3^{\circ}$ e $5^{\circ}$ anos no que concerne a três exigências cognitivas necessárias ao entendimento da probabilidade: compreender a aleatoriedade, formar o espaço amostral e comparar e quantificar probabilidades.

Nos estudos, os autores julgam jogos como "situações-problema a partir das quais podem ser tratados conceitos e relações matemáticas relevantes para o ensino básico" (PERNAMBUCO, 2012, p. 35).

À luz do Método Clínico Piagetiano, ambas as pesquisas apontaram que a maioria das crianças utilizou o significado intuitivo da probabilidade e cometeram o erro de recência positiva ou de recência negativa; as crianças mais velhas apresentaram argumentos mais coerentes, no entanto seus conhecimentos não estavam consolidados. Apesar das suas facilidades em identificar eventos impossíveis, pouco e muito prováveis, vislumbramos que o ensino de probabilidade pode dar-se desde os anos iniciais, a partir da utilização de jogos, considerando noções intuitivas que as crianças já possuem e possibilitando discussões que permitam avanços em seus raciocínios probabilísticos (BATISTA; BORBA, 2016).

As autoras do T06 sustentaram sua investigação na abordagem fenomenológica que, ao efetuar o movimento hermenêutico, põe em "[...] evidência a linguagem, entendida como expressão do sentir, e o discurso, entendido como articulação daquilo que faz sentido" (BICUDO, 2006, p. 112). Assim, buscaram compreender os sentidos e os significados da pesquisa em Ensino de Probabilidade e Estatística nos trabalhos publicados no III 
Seminário Internacional de Pesquisa em Educação Matemática. Segundo as autoras, os resultados da análise rigorosa permitiram compreensões e interpretações sobre o sentido e o significado do que está sendo explicitado nos textos analisados. Argumentando, ainda, que não há indício de formação de grupos de pesquisa sobre este tema em termos de região ou instituições. Além disso, salientamos que as pesquisas em Ensino de Probabilidade e Estatística requerem um trabalho de investigação que avance em direção a uma discussão teórica que apresente elementos, interpretações e resultados para além do explicitado nos textos já estudados (MENEGHETT; BATISTELA; BICUDO, 2011). Diz-nos Gadamer: "O fato de que um texto transmitido se converta em objeto de interpretação quer dizer, para começar, que coloca uma pergunta ao intérprete. Compreender um texto quer dizer compreender essa pergunta" (GADAMER, 1997, p.544).

As autoras do T09 utilizaram a Teoria Histórico-Cultural, ou Sociointeracionista, de Vygotsky (2001), tendo como objetivo apresentar uma pesquisa sobre o desenvolvimento de conceitos sobre combinatória, estatística e probabilidade, desenvolvidos a partir do jogo "Corrida de Cavalos", na perspectiva da resolução de problemas. Desse modo, a interlocução entre a formação de conceitos na perspectiva vygotskyana, a formação de conceitos específicos do campo da combinatória, da estatística e da probabilidade e a dinâmica no processo de ensino e de aprendizagem possibilitam um trabalho significativo em contexto escolar (SANTOS; SANTOS, 2016). Nessa perspectiva, vale a pena explorar, nas relações de ensino, o desenvolvimento de conceitos sobre combinatória, estatística e probabilidade, uma vez que a linguagem, a mediação e a interação estão implícitas nas ações desenvolvidas neste contexto da sala de aula entre professor e estudantes e entre estudantes (VYGOTSKY, 2001). Assim, ensinar tais conceitos, portanto, significa "um trabalho com signos, um trabalho de significação por excelência, que implica incansáveis gestos indicativos nas orientações de olhares, nas configurações dos gestos, nas formas de referir, de conceituar" (SMOLKA, 2010, p. 128).

Os autores do T21 utilizaram a Análise Estatística Implicativa (ASI) para analisar a relação mantida por 33 estudantes do Curso de Licenciatura em Matemática, em uma Universidade Pública do Estado da Paraíba, com a Probabilidade e seus conceitos. Segundo os autores, "A Análise Estatística Implicativa como quadro teórico para análise de dados multidimensionais permite visualizar, organizar, construir modelos e explicar os 
fenômenos que estão associados a esses dados" (CAVALCANTE; ANDRADE; RÉGNIER, 2016, p. 449). Os resultados dessa investigação apontaram ao menos duas características sobre os conceitos de Probabilidade: a fragilidade com que os futuros professores falam sobre as noções básicas do conceito de Probabilidade e a ausência de discussões sobre o ensino de Probabilidade parecem contribuir para incompreensão dos sujeitos frente a questões desta natureza.

Dadas essas características sobre a Probabilidade apontadas no resultado, Cazorla (2009) pontua uma série de entraves na formação do Licenciando em Matemática em relação à Educação Estatística. Para a autora, muitos licenciandos adquirem conhecimentos sobre conceitos de Estatística e Probabilidade, já que estas disciplinas estão presentes nos Projetos Pedagógicos de Curso das Instituições de Ensino Superior, no entanto, esses são, por vezes, insuficientes para o exercício da docência, uma vez que exigem, para além dos conhecimentos dos conteúdos, também conhecimentos didáticos específicos. De modo semelhante, Gras, Regnier et al. (2013) discutem que a Educação Estatística na formação docente é um processo de apropriação das suas ferramentas, tanto como objeto a ensinar como instrumento para produção do conhecimento de conteúdos relacionados à Estatística, Probabilidade e Combinatória.

Os autores do T25 utilizaram a Teoria da Aprendizagem Significativa, estudada e publicada pelo psicólogo norte-americano David Paul Ausubel (1918-2008) na década de 1960. A Teoria da Aprendizagem Significativa "propõe explicar os mecanismos internos que ocorrem na mente humana com relação ao aprendizado e à estruturação do conhecimento" (BRUM; SILVA, 2015, p. 16). Nesse sentido, os pressupostos de Ausubel (2006) utilizaram-se dos contributos que mapas conceituais podem trazer para os estudantes, ao abordar o que eles já conhecem em articulação com a nova proposta de conteúdo (organizador prévio) (RIBEIRO et al., 2018), A partir dos pressupostos desta teoria, os autores apresentaram a análise de mapas conceituais elaborados por alunos do segundo ano do Ensino Médio, de forma a compreender os conhecimentos prévios sobre probabilidade adquiridos pelos participantes e o seu desenvolvimento progressivo após a aplicação de um organizador prévio.

Os mapas conceituais são entendidos, por Moreira e Masini (2001, p. 51), como “instrumentos que mostram relações hierárquicas entre conceitos de uma disciplina e que 
derivam sua existência da própria estrutura da disciplina". De forma semelhante, Novak (2000) argumenta que o mapa conceitual passa a ser um instrumento de representação de saberes por parte dos estudantes, e, consequentemente, dá suporte aos professores em diferentes áreas na busca em facilitar os processos de ensino, ao oportunizar aos estudantes a capacidade de utilizar esse conhecimento no processo de aprendizagem dos conteúdos de Probabilidade, já que "o valor educativo dos mapas conceituais está no reconhecer e valorizar a mudança no significado da experiência humana” (NOVAK; GOWIN, 1996, p. 58). Por meio dos mapas conceituais, os resultados encontrados evidenciam que os estudantes apresentaram indícios de aprendizagem significativa após a aplicação do organizador prévio para o conteúdo de Probabilidade, pois perceberam a integração de novas ideias aos conceitos que eles já conheciam, bem como a capacidade de diferenciar as novas ideias existentes em sua estrutura cognitiva (RIBEIRO et al., 2018).

Nos demais trabalhos em que os(as) autores(as) não assumiram uma perspectiva teórica, os textos sinalizaram traços comuns entre as pesquisas selecionadas, sendo que todas apresentaram uma seção discutindo o ensino de Probabilidade e fizeram uso de documentos oficiais, como Parâmetros Curriculares Nacionais, Leis de Diretrizes e Bases da Educação ou Diretrizes Curriculares Nacionais e Base Nacional Comum Curricular (BNCC), atualmente em processo de implementação no Brasil. A preocupação com o ensino de Probabilidade em diferentes níveis de ensino é notória nos trabalhos, mas nos chamou atenção o texto de Viali e Silva (2016) sobre a necessidade de iniciar o ensino e a aprendizagem da estatística e da probabilidade na infância; tal necessidade foi verificada nos trabalhos que focaram nos anos iniciais do Ensino Fundamental, como, por exemplo, Campos e Carvalho (2016), Lopes e Mendonça (2016), fundamentando suas necessidades nos estudos de Bryant e Nunes (2012), Gal (2004), Fischbein (1975), entre outros que recomendam o início do ensino de probabilidade quando a criança é pequena, ou seja, desde os anos iniciais da escolaridade.

\section{Em relação às abordagens metodológicas assumidas pelos autores nos trabalhos}

Que estratégia(s) utilizar para compreender e/ou problematizar a experiência de ensinar conceitos probabilísticos em diferentes níveis de ensino e contexto no ambiente da sala de aula? Esta questão traz a discussão para o terreno das abordagens metodológicas, 
isto é, uma diversidade de estratégias gerais da investigação. De modo geral, entre o total de 29 trabalhos analisados, apenas sete textos assumiram uma abordagem qualitativa (T03, T09, T14, T22, T25, T27 e T29). Esses textos justificaram a escolha por essa abordagem, pois é pautada na "[...] compreensão dos comportamentos a partir da perspectiva dos sujeitos da investigação" (BOGDAN; BIKLEN, 1994, p. 16). Sobre este tipo de abordagem, Oliveira (2011, p. 28) classifica "como sendo um processo de reflexão e análise da realidade, através da utilização de métodos e técnicas para compreensão detalhada do objeto de estudo em seu contexto histórico e/ou segundo a sua estruturação”.

As outras pesquisas não explicitaram a metodologia adotada, mas pela maneira como foi conduzida a análise dos dados inferimos a preponderância da pesquisa qualitativa, uma vez que as mesmas reconheceram "a não neutralidade do pesquisador que, no processo interpretativo, vale-se de suas perspectivas e filtros vivenciais prévios dos quais não consegue se desvencilhar" (GARNICA, 2012, p. 99). Ou seja, nesta abordagem, "o pesquisador se propõe a participar e interpretar as informações que ele obtém a partir da pesquisa” (MARTINS; BICUDO, 1989, p. 23).

A partir da concepção apresentada por Viali e Silva (2016) e Oliveira (2011), quanto à metodologia, são várias as abordagens possíveis representadas nos textos dos trabalhos analisados, contudo, por questões de espaço exigido pelas normas da revista, vamos explanar as quais apareceram com mais frequência. Por exemplo, resolução de problemas, conforme Botelho (2011), ou jogos, o que pode ser visto nos trabalhos de Batista e Borba (2015), Estevam (2013) e Santos e Santos (2016). O uso de projetos para o ensino de estatística na infância é relatado em Souza (2008), enquanto que a utilização de recursos computacionais, como o TinkerPlots, é abordada no trabalho de Monteiro e Martins (2016). Alvarenga, Nobre e Paiva (2016) fazem um levantamento sobre recursos computacionais que podem ser utilizados para a educação estatística de alunos do primeiro ano do ensino fundamental. A abordagem metodológica que preponderou foi a realização de jogos como um recurso pedagógico, que pode constituir-se em situações de resolução de problemas capazes de mobilizar a interdisciplinaridade e a ludicidade na Educação Básica, aparecendo em cinco pesquisas (T07, T09, T13, T17 e T28), favorecendo processos de ensino dos conceitos e noções de Probabilidade, uma vez que:

(...) o jogo propicia situações que, podendo ser comparadas a problemas, exigem soluções vivas, originais, rápidas. Nesse processo, o planejamento, a busca por 
melhores jogadas e a utilização de conhecimentos adquiridos anteriormente propiciam a aquisição de novas ideias, novos conhecimentos (...) (SMOLE, 1996, p. 138).

Conforme Borba, Batista e Azevedo (2015), o uso de diferentes jogos de Probabilidade podem ser uma boa oportunidade para estudantes da Educação Infantil e Anos Iniciais pensarem de maneira informal em noções probabilísticas, e, particularmente, no levantamento de espaços amostrais, "incentivando as crianças a representarem seus dados de formas diversificadas - tais como desenhos, tabelas, gráficos e árvores de possibilidades, bem como o uso de manipulativos" (SANTANA; BORBA, 2010, p. 10).

Em suma, as cinco pesquisas direcionaram suas investigações para responder a uma constatação elucidada no relatório de Bryant e Nunes (2012), em que os autores apontaram que há carência de estudos que analisem procedimentos de crianças em aleatoriedade por meio de jogos. Esse relatório foi o ponto de partida para que os autores dessas cinco investigações se debruçassem na perspectiva de a ludicidade dos jogos trazerem leveza à atividade e maior desejo de participação das crianças (BATISTA; BORBA, 2016; SANTOS; SANTOS, 2016; MONTEIRO; MARTINS, 2016).

Nessa perspectiva, o jogo possibilita "às crianças desenvolver a capacidade de organização, análise, reflexão e argumentação, uma série de atitudes como: aprender a ganhar e a lidar com o perder, aprender a trabalhar em equipe, respeitar regras, entre outras" (BRASIL, 2014, p.5).

Além dessas inegáveis habilidades, os estudos de Conti e Bôas (2019, p. 387), por meio do jogo, apontaram que "as crianças se manifestam espontaneamente, sem censura nem convenções, criam estratégias, buscam soluções e levantam hipóteses". Outro benefício é a socialização que os jogos promovem, a fim de que as crianças aprendam a conviver e a respeitar as outras crianças e culturas.

O estudo de caso foi abordado em T05 e T14, que utilizaram Lüdke e André (1986, p. 17) para defini-lo como:

O caso é sempre bem delimitado, devendo ter seus contornos claramente definidos no desenrolar do estudo. O caso pode ser similar a outros, mas é ao mesmo tempo distinto, pois tem um interesse próprio, singular [...] O interesse, portanto, incide naquilo que ele tem de único, de particular, mesmo que posteriormente venham a ficar evidentes certas semelhanças com outros casos ou situações. Quando queremos estudar algo singular, que tenha um valor em si mesmo, devemos escolher o estudo de caso. 
$\mathrm{Na}$ abordagem qualitativa, no contexto amplo da pesquisa realizada por Conti (2016) e Silva (2011), optaram pelo estudo de caso, que, segundo Ponte (2006, p. 2), tem como objetivos "conhecer uma entidade bem definida como uma pessoa, uma instituição, um curso, uma disciplina, um sistema educativo, uma política ou qualquer outra unidade social" e também “compreender em profundidade o 'como' e os 'porquês' dessa entidade, evidenciando sua identidade e características próprias, nomeadamente nos aspectos que interessam ao pesquisador".

Outra abordagem metodológica utilizada foi a Resolução de Problemas, no T03, "tendo como metodologia a resolução de problemas em uma perspectiva investigativa e, como foco, as questões estocásticas" (SANTOS; GRANDO, 2011, p. 561); e T04 "o ponto de partida para a construção do conceito de probabilidade é uma situação de jogo associada à metodologia de resolução de problemas" (LOPES, 2011, p. 607), na qual os autores utilizam Allevato e Onuchic (2014, p. 48) sobre o uso da Metodologia de EnsinoAprendizagem-Avaliação de Matemática por meio da Resolução de Problemas, a qual tem se mostrado "como um contexto bastante propício à construção de conhecimento, colocando o aluno no centro das atividades de sala de aula, sem prescindir do fundamental papel desempenhado pelo professor como organizador e mediador". Além disso, a Metodologia apresenta uma concepção mais atual de avaliação, em que a mesma é realizada durante toda a resolução de problemas, "integrando-se ao ensino com vistas a acompanhar o crescimento dos alunos, aumentando a aprendizagem e reorientando as práticas de sala de aula quando necessário” (ALLEVATO, ONUCHIC, 2009, p.139).

Os autores do T02 e T19 adotaram, na condução da investigação, a abordagem metodológica da pesquisa-ação, uma vez que "possibilita ao pesquisador mergulhar no ambiente a ser estudado para mudá-lo em direções que permitam a melhoria das práticas e maior liberdade de ação e de aprendizagem dos participantes" (FIORENTINI; LORENZATO, 2006, p. 112). Para esses autores, a pesquisa-ação é um processo investigativo de intervenção em que a prática investigativa, a reflexiva e a educativa caminham juntas, por uma estrutura coletiva, participativa e ativa no nível da captação da informação uma vez que, ao investigar a prática educativa, produzem-se compreensões e orientações que são imediatamente utilizadas em sua transformação, gerando novas situações de investigação (SOUZA, 2016; CAZORLA; GUSMÃO; KATAOKA, 2011). 
Desse modo, trata-se de uma modalidade de pesquisa que torna o participante da ação um pesquisador de sua própria prática, portanto exige a coparticipação e a ação das pessoas envolvidas na solução do problema investigado, e o pesquisador um participante que intervém nos rumos da ação, orientado pela pesquisa em ação (THIOLLENT, 1986).

Dois trabalhos optaram pela abordagem fenomenológica em suas investigações. No primeiro, Moura e Samá (2016, p. 532) justificaram a escolha pela abordagem metodológica fenomenológica, pois a mesma "permite o foco nos significados específicos atribuídos ao que observamos, almejando compreender o fenômeno em sua essência, na medida em que este é vivido, experienciado e conscientemente percebido pelos estudantes". Na segunda, Meneghetti, Batistela e Bicudo (2011, p. 817) analisaram os dados em um movimento hermenêutico, o qual põe em "[...] evidência a linguagem, entendida como expressão do sentir, e o discurso, entendido como articulação daquilo que faz sentido". Em suma, nas duas pesquisas "o pesquisador se propõe a participar e interpretar as informações que ele obtém a partir da pesquisa" (MARTINS; BICUDO, 1989, p. 23).

\section{CONCLUSÃO E IMPLICAÇÕES}

Nosso objetivo, no presente artigo, consistiu em identificar, caracterizar e compreender o que vem sendo investigado nas produções científicas brasileiras que abordam Ensino de Probabilidade nas edições especiais de Educação Estatística. Assim, oferecendo àqueles que estudam e/ou pesquisam a respeito do ensino de Probabilidade, em diferentes níveis de ensino, um panorama detalhado do que se investigou em nosso país entre os anos de 2011 a 2019. Pretendemos, também, oferecer ao leitor a análise e a sistematização dos fundamentos teóricos e metodológicos assumidos pelos autores que abordaram o Ensino de Probabilidade.

Finalizando, em nosso ponto de vista, esse artigo pode propiciar o debate de novas ideias relevantes ao proporcionar uma compreensão abrangente do campo de estudo da Educação Estatística, laçando olhar para além das revistas aqui analisadas, de eventos internacionais que discutem a temática em questão, por meio de seu estado da arte ou estado do conhecimento com relação aos congressos brasileiros, por intermédio da discussão de suas práticas pedagógicas, de suas contribuições para a formação de professores que ensinam matemática e de seu papel na Educação Matemática. 
Por conseguinte, o presente estudo buscou mostrar que ainda há muito que pesquisar sobre o Ensino de Probabilidade na Educação Estatística, e esperamos que esse estudo bibliográfico, sobre as sete revistas que editaram e publicaram edições especiais sobre Educação Estatística, possa estimular a discussão e encorajar a condução de estudos e investigações relacionadas à formação inicial e continuada para ensinar Probabilidade e o uso de tecnologias digitais no ensino de Probabilidade.

\section{REFERÊNCIAS}

ALMEIDA, C. M. C.; FARIAS, L. M. S. Observações acerca de uma engenharia didática de formação para o ensino de probabilidade. ReBECEM, Cascavel, (PR), v.3, n.2, p. 566594, ago. 2019.

ALMOUlOUD, S. A. Fundamentos da didática da matemática. Edição atualizada. Curitiba: Ed. UFPR, 2010.

APPOLINÁRIO, F. Dicionário de metodologia científica: um guia para a produção do conhecimento científico. São Paulo, Atlas, 2009.

ARAÚJO, A. F. Q.; CARVALHO, J. I. F. A inter-relação entre a estatística e a probabilidade: um estudo sobre os conhecimentos de professores de matemática do ensino médio sobre a curva normal. ReBECEM, Cascavel, (PR), v.3, n.2, p. 263-289, ago. 2019.

AUSUBEL, D. P. Aquisição e retenção de conhecimentos: uma perspectiva cognitiva. Tradução Lígia Teopisto. Lisboa: Plátano, 2006. Edições Técnicas. Título original: The acquisition and retention of knowledge: a cognitive view.

BARDIN, L. Análise de conteúdo. Lisboa: Edições 70, 2009.

BATISTA, R.; BORBA, R. E. S. R. No jogo é a moeda que diz, não é a gente que quer não: o que dizem crianças sobre a probabilidade. VIDYA, v. 36, n. 2, p. 237-255, jul./dez., 2016.

BATISTA, R.; BORBA, R.E. S. R. Lançando dados e moedas: relação de (in)dependência sob a ótica de crianças dos anos iniciais. EM TEIA - Revista de Educação Matemática e Tecnológica Ibero-americana, v. 7, n. 1, 2016.

BORBA, R.; BATISTA, R.; AZEVEDO, J. Levantando possibilidades para o desenvolvimento dos raciocínios probabilístico e combinatório de crianças em anos iniciais de escolarização. In: BORBA, R.; GUIMARÃES, G. (Org.). Pesquisa e atividades para o aprendizado matemático na educação infantil e nos anos iniciais do ensino fundamental. Brasília: SBEM, 2015.

BORTOLOSSI, H. J. O uso do software gratuito geogebra no ensino e na aprendizagem de estatística e probabilidade. VIDYA, v. 36, n. 2, p. 429-440, jul./dez., 2016.

BRASIL. Secretaria de Educação Básica. Pacto Nacional pela Alfabetização na Idade Certa: jogos na alfabetização matemática. Ministério da Educação. Diretoria de Apoio à Gestão Educacional. Brasília: MEC, SEB, 2014. 
BRUM, W. P.; SILVA, S. C. R. A utilização de uma ueps no ensino de matemática: uma investigação durante a apresentação do tema probabilidade. Aprendizagem Significativa em Revista, v. 5, n. 1, p. 15-32, 2015.

BRYANT, Peter; NUNES, Terezinha. Children's understanding of probability: a literature review. Oxford: Nuffield Foundation, 2012. Disponível em: $<$ http://www.nuffieldfoundation.org/sites/default/files/files/Nuffield_CuP_FULL_REPO RTv_FINAL.pdf $>$. Acesso em: 13 ago. 2020.

CAMPOS, T. M. M.; CARVALHO, J. I. F. Probabilidade nos anos iniciais da educação básica: contribuições de um programa de ensino. EM TEIA - Revista de Educação Matemática e Tecnológica Ibero-americana, v. 7, n. 1, 2016.

CARRAHER, T. N. O método clínico usando os exames de Piaget. 5. ed. São Paulo: Cortez, 1998.

CAVALCANTE, J. L.; ANDRADE, V. L. V. X.; RÉGNER, J. O conceito de probabilidade na formação docente: uma reflexão apoiada pela análise estatística implicativa. VIDYA, v. 36, n. 2, p. 441-455, jul./dez., 2016.

CAZORLA, I. M. O ensino de estatística no Brasil. Sociedade Brasileira de Educação Matemática. 2009. Disponível em: <https://goo.gl/C5OE9a>. Acesso em: 12 ago. 2020.

CAZORLA, I. M.; GUSMÃO, T. C. KATAOKA, V. Y. Validação de uma sequência didática de probabilidade a partir da análise da prática de professores, sob a ótica do enfoque ontossemiótico. Bolema, Rio Claro (SP), v. 24, n. 39, p. 537-560, ago. 2011.

CHAVALLARD, Y. Conceitos fundamentais da didática: perspectivas trazidas por uma abordagem antropológica. In: BRUN, J. Didáctica das matemáticas. Lisboa: Horizontes Pedagógicos, 1996.

CHAVALLARD, Y. L' analise dês pratiques enseignantes em théorie antropologique du didactique. Recherches em Didactique des Mathematiques. La Pensée Sauvage Editions, Grenobre, França, v. 19, n. 2, p. 221-265, 1999.

CHAVALLARD, Y.; BOSCH, M.; GASCÓN, J. Estudar matemáticas: o elo perdido entre o ensino e a aprendizagem. Porto Alegre: Artes Médicas, 2001.

CONTI, K. C. Educação estatística num contexto colaborativo: ensinar e aprender probabilidade. Educ. Matem. Pesq., São Paulo, v.18, n.3, p. 1117-1140, 2016.

CONTI, K. C.; BÔAS, S. G. V. Acaso e probabilidades nos anos iniciais: potencial dos jogos como mediadores na construção do conhecimento. ReBECEM, Cascavel, (PR), v.3, n.2, p. 379-399, ago. 2019.

CRESWELL, J. W. Projeto de pesquisa: métodos qualitativo, quantitativo e misto. Tradução Luciana de Oliveira da Rocha. 3. ed. Porto Alegre: Artmed, 2007.

FIORENTINI, D.; LORENZATO, S. Investigação em educação matemática: percursos teóricos e metodológicos. Campinas: Autores Associados, 2006. 226 p.

FISCHBEIN, E. The intuitive sources of probabilistic thinking in children. Dordrecht, The Netherlands: Reidel, 1975. 
GADAMER, H. G. Verdade e método: traços fundamentais de uma hermenêutica filosófica. Tradução F. P. Meurer. Petrópolis: Vozes, 1997.

GAL, Iddo. Toward 'probability literacy' for all citizens. In: JONES, Graham. Exploring probability in school: challenges for teaching and learning. Netherlands: Kluwer Academic Publishers, 2004. p. 43-71.

GARNICA, A V M. História oral e educação matemática. In: BORBA, M.; ARAÚJO, J.L. Pesquisa qualitativa em educação matemática. 4.ed. Belo Horizonte: Autêntica, 2012.

GODINO, J. D. Un enfoque ontológico y semiótico de la cognición matemática. Recherches en Didactique des Mathématiques, Paris, v. 22, n. 2,3, p. 237-284, 2002.

GODINO, J. D.; BATANERO, C.; FONT, V. .Um enfoque onto-semiótico do conhecimento e a instrução matemática. Acta Scientiae, v.10, n.2, jul./dez. 2008.

GRAS, R.; RÉGNIER, J.-C., MARINICA, C., GUILlET, F. Analyse statistique implicative. Méthode exploratoire et confirmatoire à la recherche de causalités. Toulouse: Éditions Cépaduès. 2013.

GUSMÃO, T. Los procesos metacognitivos en la comprensión de las prácticas de los estudiantes cuando resuelven problemas matemáticos: una perspectiva ontossemiótica. 2006. 366p. Tese (Doutorado em Didáctica de las Matemáticas) - Faculdade de Ciências da Educação, Universidade de Santiago de Compostela, Espanha, 2006.

GUSMÃO, T.; FONT, V.; CAJARAVILLE, J. Análise cognitivo e metacognitivo de práticas matemáticas de resolução de problemas: $\mathrm{O}$ caso Nerea. Educação Matemática Pesquisa, São Paulo, v. 11, n. 1, p. 9-43, 2009.

JÚNIOR, A. P. O.; CIABOTTI, V. Discussão sobre o processo de elaboração de um livro paradidático para o ensino de probabilidade à luz da teoria antropológico do didático. REnCiMa, v.9, n.2, p. 52-71, 2018.

LOPES, C. E.; MENDONÇA, L. O. Prospectivas para o estudo da probabilidade e da estatística no ensino fundamental. VIDYA, v. 36, n. 2, p. 293-314, jul./dez., 2016.

LOPES, C. E.; SOUZA, L. O. Aspectos filosóficos, psicológicos e políticos no estudo da probabilidade e da estatística na educação básica. Educ. Matem. Pesq., São Paulo, v.18, n.3, p. 1465-1489, 2016.

LOPES, J. M. Uma proposta didático-pedagógica para o estudo da concepção clássica de probabilidade. Bolema, Rio Claro (SP), v. 24, n. 39, p. 607-628, ago. 2011.

MARTINS, J.; BICUDO, M. A. V. A pesquisa qualitativa em psicologia: fundamentos e recursos básicos. São Paulo: Moraes, 1989.

MENEGHETTI, R. C. G.; BATISTELA, R. F.; BICUDO, M. A. V. A pesquisa sobre o ensino de probabilidade e estatística no Brasil: um exercício de metacompreensão. Bolema, Rio Claro (SP), v. 24, n. 40, p. 811-833, dez. 2011.

MONTEIRO, C. E. F.; MARTINS, M. N. P. Possibilidades de recursos para o ensino de probabilidade nos anos iniciais. EM TEIA - Revista de Educação Matemática e Tecnológica Ibero-americana, v. 7, n. 1, 2016.

MOREIRA, M. A; MASINI, E F. S. Aprendizagem significativa: a teoria de David 
Ausubel. São Paulo: Centauro, 2001.

MOURA, G. M.; SAMÁ, S. Ilusão da equiprobabilidade, aleatoriedade e convergência nos processos cognitivos envolvidos no raciocínio probabilístico. VIDYA, v. 36, n. 2, p. 523538, jul./dez., 2016.

NAGAMINE, C. M. L.; HENRIQUES, A.; UTSUMI, M. C. CAZORLA, I. M. Análise praxeológica dos passeios aleatórios da Mônica. Bolema, Rio Claro (SP), v. 24, n. 39, p. 451-472, ago. 2011.

NÓBREGA, G. M. M.; SPINILLO, A. G. A noção de possível na probabilidade e na combinatória em estudantes do ensino fundamental. EM TEIA - Revista de Educação Matemática e Tecnológica Ibero-americana, v. 7, n. 1, 2016.

NOVAK, J. D; GOWIN, D. B. Aprender a aprender. Lisboa: Plátano Técnicas. 1996.

OLIVEIRA, C. R.; CORDANI, L. K. Julgando sob incerteza: heurísticas e vieses e o ensino de probabilidade e estatística. Educ. Matem. Pesq., São Paulo, v. 18, n. 3, p. 1265-1289, 2016.

OLIVEIRA, M. M. Como fazer projetos, relatórios, monografias, dissertações e teses. 5. ed. Rio de Janeiro: Elsevier, 2011.

ONUCHIC, L. R.; ALLEVATO, N. S. G. Pesquisa em resolução de problemas: caminhos, avanços e novas perspectivas. BOLEMA. Boletim de Educação Matemática. UNESP. Rio Claro, v. 25, p. 73-98, 2011. Disponível em: http://www.redalyc.org/pdf/2912/ 291223514005.pdf . Acesso em: 13 ago. 2020.

PERNAMBUCO. Parâmetros para Educação Básica do Estado de Pernambuco: Parâmetros Curriculares de Matemática para o Ensino Fundamental e Médio. Secretaria de Educação. UNDIME:PE, 2012, 145 p.

PRODANOV, C. C.; FREITAS, E. C. de. Metodologia do trabalho científico: métodos e técnicas da pesquisa e do trabalho acadêmico. 2. ed. Novo Hamburgo: Feevale, 2013.

PUGLISI, M. L.; FRANCO, B. Análise de conteúdo. 2. ed. Brasília: Líber Livro, 2005.

RIBEIRO, N. P.; MORAIES, H. A.; DAMIN, W.; LUCCAS, S. Mapas conceituais na compreensão da aprendizagem significativa do conteúdo de probabilidade. REnCiMa, v.9, n.2, p. 167-181, 2018.

RITTER, D.; BULEGON, A. M. Uma revisão de literatura sobre estudos relativos à probabilidade geométrica. VIDYA, v. 36, n. 2, p. 581-597, jul./dez., 2016.

ROSA, P. R. S. Uma introdução à pesquisa qualitativa em ensino de ciências. Campo Grande: UFMS, 2013.

SANTANA, M. R. M.; BORBA, R. Como a probabilidade tem sido abordada nos livros didáticos de matemática de anos iniciais de escolarização. In: ENCONTRO NACIONAL DE EDUCAÇÃO MATEMÁTICA, 10., 2010, Salvador: Anais [...]. Salvador: ENEM, 2010. p. 1-11.

SANTANA, M. R. M.; BORBA, R. E. S. R. O ensino de probabilidade nos anos iniciais: um olhar sobre a abordagem nos livros didáticos. EM TEIA - Revista de Educação Matemática e Tecnológica Ibero-americana, v. 7, n. 1, 2016. 
SANTOS, J. A. F. L.; GRANDO, R. C. O movimento das ideias probabilísticas no ensino fundamental: análise de um caso. Bolema, Rio Claro (SP), v. 24, n. 39, p. 561-584, ago. 2011.

SANTOS, J. L.; SANTOS, E. V. Um jogo e a linguagem: possibilidades para a produção de conceitos sobre combinatória, estatística e probabilidade com alunos do $4^{\circ}$ ano do ensino fundamental. EM TEIA - Revista de Educação Matemática e Tecnológica Iberoamericana, v. 7, n. 1, 2016.

SILVA, M. A. A presença da estatística e da probabilidade no currículo prescrito de cursos de licenciatura em matemática: uma análise do possível descompasso entre as orientações curriculares para a educação básica e a formação inicial do professor de matemática. Bolema, Rio Claro (SP), v. 24, n. 40, p. 747-764, dez. 2011.

SMOLE, K. C. S. A matemática na educação infantil. A teoria das inteligências múltiplas na prática escolar. Porto Alegre: Artes Médicas, 1996.

SMOLKA, A. L. Ensinar e significar: as relações de ensino em questão ou das (não)coincidências nas relações de ensino. In: SMOLKA, Ana Luiza; NOGUEIRA, Ana Lúcia (Orgs.). Questões de desenvolvimento humano: práticas e sentidos. Campinas, SP: Mercado de Letras, 2010. p. 107-128.

SOUZA, G. C.; SOUZA, L. O. Arranjos com repetição e simulações probabilísticas: obstáculos de aprendizagem. REVEMAT, Florianópolis (SC), v.14, p.1-16, 2019.

SOUZA, L. O. Formação de professores para o ensino de probabilidade: simulação conectando ideias estatísticas. VIDYA, v. 36, n. 2, p. 377-395, jul./dez., 2016.

THIOLLENT, M. Metodologia da pesquisa-ação. São Paulo: Cortez, 1986.

TOZONI-REIS, M. F. C. Metodologia da pesquisa. 2. ed. Curitiba: IESDE Brasil, 2009.

TRIPP, D. Pesquisa-ação, uma introdução metodológica. Educação e Pesquisa, São Paulo, v. 31, n. 3, p. 443-466, 2005.

VIALI, L.; SILVA, M. M. Sobre a necessidade de se iniciar o ensino/aprendizagem da estatística e da probabilidade na infância. EM TEIA - Revista de Educação Matemática e Tecnológica Ibero-americana, v. 7, n. 1, 2016.

VYGOTSKY, L. A construção do pensamento e da linguagem. Tradução Paulo Bezerra. São Paulo: Martins Fontes, 2001. 